\title{
A Plant-Based Diet Prevents and Treats Chronic Kidney Disease
}

\author{
Stewart D Rose* and Amanda J Strombom \\ Plant-based diets in Medicine, USA
}

Submission: January 03, 2019; Published: January 23, 2019

*Corresponding author: Stewart D Rose, Plant-Based Diets in Medicine, 12819 SE 38th St, \#427, Bellevue, WA 98006, Washington, USA.

\begin{abstract}
Interest in the dietary treatment of chronic kidney disease has been growing as its incidence has been increasing. Chronic Kidney Disease (CKD) is now the 8th leading cause of death in the United States and its treatment consumes substantial amounts of medical resources and money. Several lines of epidemiological research have shown a lower risk of chronic kidney disease among vegetarians. It also shows a substantially increased risk among omnivores, especially those who eat red and processed meats. Although the practice started long ago, research on the use of a low-protein plant-based diet to treat chronic kidney disease diet has intensified in recent years. This research has shown that a low-protein vegetarian diet is safe and efficacious at both treating and slowing the progression of chronic kidney disease. Treatment with a low-protein vegetarian diet, often supplemented with keto analogues, has been shown to reduce acidosis, phosphotemia, uremia, proteinuria and to slow progression. Research shows that this treatment does not result in malnutrition. Research has also shown that larger amounts of plant protein than animal protein can be consumed, without deleterious effects. Treatment with a low protein vegetarian diet also has the advantage of preventing and treating common comorbidities such as type 2 diabetes and coronary artery disease.
\end{abstract}

Keywords: Acidosis; Chronic kidney disease; Keto Analogues; Kidney disease; Phosphotemia; Plant-Based diet; Proteinuria; Uremia; Vegetarian; Vegan

Abbrevations: AGE: Advanced Glycation End Product; CKD: Chronic Kidney Disease; DAL: Dietary Acid Load; DM: Diabetes Mellitus; ESRD: End Stage Renal Disease; FGF 23: Fibroblast Growth Factor 23; GFR: Glomerular Filtration Rate; HD: Hemodialysis; KD -Keto Diet; LPD: Low Protein Diet; PCB: Polychlorinated Biphenyl; PCDF: Polychlorinated Dibenzofuran; PCDD: Polychlorinated Dibenzo-P-dioxin; POP: Persistent Organic Pollutant RPF: Renal Plasma Flow; SAF: Skin Auto Fluorescence; URM: Uremic Retention Molecule; VLPD: Very Low Protein Diet.

\section{Introduction}

Chronic kidney disease is a major health care problem and slowing its progression to end-stage renal disease (ESRD) has obvious clinical and economic benefits. [1-3] Diet is the largest risk factor for CKD patients for death and disability [4,5]. A lowprotein diet (LPD) as a therapeutic measure in chronic kidney disease (CKD) was suggested by Beale as early as 1869, [6] and the first attempt to experimentally evaluate an LPD in humans was done by Smith in 1926 [7].

For at least a century, chronic uraemia has been considered an example of "protein intoxication." Thus, in the history of renal medicine, low protein diets have been attempted as a way to correct the metabolic alterations caused by kidney failure as much as possible $[8,9]$. Indeed, the first systematic studies on low-protein diets in uraemia patients started with the observation that a protein-restricted diet was effective in reducing the symptoms of "uraemic toxicity" and that it was even able to prolong life [10-13]. In the mid-1960s, Giordano and Giovannetti were the first to show that a low-protein diet was able to reduce almost all uraemic signs and symptoms [14].

By lowering blood urea and other nitrogenous waste products, a low-protein diet has favorable effects on secondary hyperparathyroidism [15], peripheral resistance to insulin, [16] hyperlipidaemia, [17] hypertension and acid-base disorders [18]. Four meta-analyses of studies on the effects of a lowprotein diet on CKD progression in diabetic and non-diabetic patients, have been performed since the early 1990s, all showing a beneficial effect [13,19-22].

Today, the main nutrition-related goals for people with chronic kidney disease involve the slowing of kidney failure progression rate, minimizing uremic toxicity and metabolic disorders of kidney failure, diminishing proteinuria, maintaining good nutritional status, and lowering the risk of complications 
including cardiovascular disease, bone disease, and disturbed blood pressure control [23]. A low-protein plant-based diet has been shown to help accomplish all of these treatment goals. Plant-based diets lend themselves well to low-protein diets suitable for CKD patients. They are a safe and efficacious treatment and still supply adequate protein while helping to prevent and treat common comorbidities [24,25].

\section{Epidemiological Studies}

Several epidemiological studies consistently show that vegans (those who follow a plant-based diet) have a decidedly lower risk of chronic kidney disease than those who consume animal derived foods. These studies also indicate that as a group those following a plant-based diet have better renal function than those following an omnivorous diet. Furthermore, epidemiological studies show that vegans also have much lower levels of risk factors for chronic kidney disease such as type 2 diabetes and hypertension.

Epidemiological studies have been able to show which foods raise and which foods lower the risk of chronic kidney disease. These studies show that while eating red meat and other sources of saturated fat raise the risk of chronic kidney disease, consuming tree nuts, legumes, fruits and vegetables lowers it. Studies comparing those who consume animal protein with those who consume equal amounts of plant protein show that those who consume plant protein have a lower risk of chronic kidney disease, indicating a significant advantage for those following a plant-based diet. The vegan diet is associated with glomerular and systemic hemodynamic changes which may be beneficial in the prevention of glomerular sclerotic changes in health and disease. Details of these studies are provided below:

One study showed that vegans had a lower glomerular filtration rate (GFR). Early elevation of the GFR plays a central role in the pathogenesis and progression of renal disease [26]. Since those following a plant-based diet have a lower GFR they are at reduced risk of incipient or early stage kidney disease. In this study omnivores were found to have a GFR of $113 \mathrm{ml} /$ $\mathrm{min} / 1.73 \mathrm{~m} 2$, the vegetarians $105 \mathrm{ml} / \mathrm{min} / 1.73 \mathrm{~m} 2$ and the vegans $100 \mathrm{ml} / \mathrm{min} / 1.73 \mathrm{~m} 2$ [27]. Omnivores also had a significantly higher mean urinary albumin excretion rate than vegans, and higher mean diastolic blood pressure than both vegans and lactovegetarians.

Vegans have been found to have a $75 \%$ decreased risk of hypertension and a 78\% reduced risk of type II diabetes [28]. Since type 2 diabetes and hypertension are both risk factors for CKD, $[29,30]$ these contribute to their lower risk of CKD. An uncontrolled diabetic and/or hypertensive patient can easily and quickly progress to an end-stage kidney disease patient [30]. A study was designed to investigate the effect of protein intake on glomerular filtration rate, and to demonstrate and evaluate the functional reserve of the kidney. Normal subjects ingesting a meat-centered diet had a significantly higher creatinine clearance than a comparable group of normal subjects ingesting a vegetarian diet [31].

An epidemiological study with a 23-year follow up period showed that diets with different dietary protein sources have different risks of incident CKD: red and processed meat are adversely associated with CKD risk, while nuts and legumes are protective against the development of CKD. Red and processed meat increased the risk of CKD by 23\% (Q5:Q1) whereas a higher dietary intake (Q5:Q1) of nuts and legumes resulted in a $19 \%$ and $17 \%$ decreased risk respectively [32]. In a study of adults aged 45-74 years old, red meat intake was strongly associated with an increased risk of the eventual development of End Stage Renal Disease (ESRD) in previously healthy people in a dose-dependent manner, with the highest quartile having a $40 \%$ increased risk over the lowest. In substitution analysis, replacing one serving of red meat with other food sources of protein was associated with a maximum relative risk reduction of $62.4 \%$. This study shows that red meat intake may increase the risk of ESRD in the general population, and that substituting alternative sources of protein may reduce the incidence of ESRD [33].

Female participants in the Nurses' Health Study who had followed a western dietary pattern (higher intake of red and processed meats, saturated fats, and sweets) had 2.17 times the risk of microalbuminuria, and a $77 \%$ greater risk of rapid estimated Glomerular Filtration Rate (eGFR) decline, compared with those following a prudent diet high in fruits, vegetables, legumes and whole grains [34]. The Western-style diet is high in animal fat with high levels of saturated fats. A cross-sectional study (Reasons for Geographic and Racial Differences in Stroke Study; REGARDS), including more than 19,000 adults over 45 years of age, found a significant association between saturated fat intake and hyperalbuminuria [35,36]. Several studies showed that the use of animal proteins compared to plant proteins induced a worsening of hard outcomes such as mortality and CKD progression $[37,38]$. In a meta-study that included six studies, healthy dietary patterns high in fruits, vegetables, legumes and whole grains were consistently associated with lower mortality or ESRD among adults with CKD, with a risk reduction of $30 \%$. (39) Substituting soy and other legumes for red meat resulted in a reduced risk for ESRD by about 50\%-62\% [39].

Looking at soy protein specifically, one study showed that independent of the quantity of protein, soy protein has significantly different renal effects from animal protein in normal humans, which could be partly explained by differences in glucagon and renal vasodilatory prostaglandin secretion [40]. This study also showed that among normal healthy subjects, the GFR, RPF (Renal Plasma Flow) and fractional clearance of albumin and IgG were significantly higher when following the animal protein diet, compared to the soy protein diet, even though the quantity of protein were the same in both groups [40]. 


\section{Intervention and Pathophysiology}

Mounting evidence indicates that dietary intervention with plant-based, alkali-inducing diets is kidney protective. The National Kidney Foundation recommends a vegetarian diet as being beneficial to CKD patients [25]. Dietary intervention was the mainstay approach for kidney failure in the first half of the 20th century, and diet manipulation was tried in its last decades $[41,42]$. Different dietary protein regimens have been proposed: conventional low-protein diets (LPDs; $0.6 \mathrm{~g} / \mathrm{kg}$ per day), very low-protein diets (VLPDs; 0.3-0.4 g/kg per day), and practically vegetarian diets supplemented with either essential amino acids or a mixture of essential amino acids and nitrogen-free ketoanalogues (keto diet or KD) [41-43].

Dietary proteins are the source of nitrogen, phosphate, and acid load. A reduction in protein consumption has been shown to result in better control of blood pressure and a decrease in proteinuria, which are major determinants of the progression of CKD [44]. Moreover, certain complications of advanced CKD, such as mineral metabolism disorders, acidosis, and oxidative stress, also involved in accelerating its progression, [45] were favorably influenced by low-protein diets $[4,45]$. In a meta-study of low-protein diets, reducing protein intake in patients with chronic kidney disease reduces the occurrence of renal death by $32 \%$ as compared with higher or unrestricted protein intake [21].

Research data indicates that the underlying renal disease and the type of diet used considerably influence the rate of progression of chronic renal failure. In relative terms, the course of the renal disease is mostly changed in patients suffering from glomerulonephritis, while in absolute terms patients suffering from polycystic kidney disease exhibit the slowest rate of progression. The comparison suggests that a low-protein diet purely based on vegetarian food might considerably slow down the overall rate of progression of chronic renal failure [46]. Diets in developed societies are largely acid producing, in part because of the proportionately greater amount of animalsourced proteins (which are acid producing) than plant-sourced proteins (which are largely base producing) [4]. The two changes in dietary protein quality therefore receiving the most attention currently is substituting plant-sourced for animal-sourced protein and substituting non-nitrogen ketoanalogue proteins in place of animal proteins.

\section{Substituting plant-sourced protein}

Studies show that the introduction of plant-derived protein in place of animal-derived protein improves metabolic acidosis, reduces kidney injury, and slows nephropathy progression, $[4,18,47]$ and that plant-based diets can delay the progression of chronic kidney disease, provide endothelial protection, help control hypertension, and decrease proteinuria, phosphotemia, acidosis, uremia, FGF 23 and hyperparathyroidism [40,48-54].
Fruits and vegetables can be used to treat CKD without producing hyperkalemia. A one-year study of fruits and vegetables in the diet in individuals with stage 4 CKD was associated with lower than baseline urine indices of kidney injury. The results indicate that fruits and vegetables improve metabolic acidosis and reduce kidney injury in stage 4 CKD without producing hyperkalemia [37]. Higher initial glomerular filtration rates (GFRs), associated with higher risk of CKD, have been demonstrated in patients without CKD on an animalprotein diet, in comparison to persons on a vegetable-based diet $[55,56]$. A study of patients without CKD on a high protein $\operatorname{diet}(1 \mathrm{~g} / \mathrm{kg} /$ day $)$ of either soy, animal protein, or animal protein diet supplemented with fiber, revealed significantly higher renal plasma flow, GFR, and proteinuria in those on the animal protein diet compared to individuals on the soy diet [40]. The transition from mixed animal-vegetable diet $(1.0$ to $1.3 \mathrm{~g} / \mathrm{kg} /$ day) to a plant-based diet $(0.7 \mathrm{~g} / \mathrm{kg} /$ day $)$ was demonstrated to be associated with a significant decrease in GFR and proteinuria in patients with non-diabetic nephrosis [57].

In another study, a diet supplying only foods of plant origin in definite proportions was used to give an essential amino acid supply satisfying the recommended dietary allowance. This was possible using an appropriate cereal legume mixture. Additional positive features of this special plant-based diet were the high ratio of unsaturated to saturated fatty acids, the absence of cholesterol, and the lower net acid production in comparison with a mixed diet. Improvements were noted in several clinical variables [57]. A study investigated the impact of a vegetarian diet on the nutritional status of hemodialysis (HD) patients. This study revealed that HD patients on vegetarian diets might have a smaller BMI, but subjective global assessment and function of daily activities were similar to those of the non-vegetarians. The haematocrit of vegetarians can be maintained with a higher erythropoietin dose [58]. A predominantly vegetarian diet may also have important beneficial effects on diabetic nephropathy without the need for a heavily restricted total protein intake [59]. This is because plant protein does not create a lower GFR the way that meat protein does. In addition, a plant-based diet can lower glycated hemoglobin even more than metformin [60]. Studies on animal models suggest that a vegetarian diet is suitable and nutritionally adequate in CKD [61-63]. Human studies confirm this [64]. Barsotti et al. [57] showed that a vegan diet is fully sufficient for a low-protein diet for CKD patients.

\section{Supplementing with Ketoanalogues}

Naturally occurring amino acids contain nitrogen, which when metabolized yield nitrogenous wastes that increase BUN and cause untoward effects on kidney function [4]. Substituting non-nitrogen ketoanalogues can allow patients to realize the benefit of dietary protein while avoiding possible untoward effects of nitrogenous wastes [45]. Furthermore, adding baseproducing plant proteins lowers levels of the pathogenic substances which induce the interstitial fibrosis that promotes 
nephropathy progression. [4,65]. Favorable metabolic effects of a ketoanalogue-supplemented diet were shown in many observational studies [43,44,66-68].

In one study by Garneata et al. [24] patients receiving a vegetarian, ketoanalogue-supplemented diet experienced an improvement of metabolic abnormalities. The authors concluded that a vegetarian ketoanalogue-supplemented diet is nutritionally safe and may defer dialysis initiation in patients with eGFR $<20 \mathrm{ml} / \mathrm{min}$ by ameliorating CKD-associated metabolic disturbances. This study brings forth useful insights into strategies using low-protein diets that can be aimed at slowing nephropathy progression [4].

A CKD study by Aparicio et al. demonstrated that in regularly and carefully monitored CKD patients, vegetarian diets with low or even a very low-protein content supplemented with keto-analogues, provided a satisfactory nutritional status. Improvements in the albumin excretion rate were noted [68]. In another study, twenty steroid-resistant, nephrotic patients were treated with a vegan, low-protein diet, supplemented with essential amino acids and ketoanalogues (supplemented vegan diet), for almost 5 months. Before the study, these patients followed an unrestricted protein, low sodium diet. Proteinuria, daily urea nitrogen excretion and creatinine clearance decreased significantly on the ketoanalogue-supplemented vegan diet without inducing clinical or laboratory signs of malnutrition [69].

A very low-protein, ketoanalogue-supplemented, vegetarian diet was also demonstrated to be safe for predialysis patients, since it exerted no detrimental effect on the short- and long-term outcomes of patients, even those already on renal replacement therapy [70]. A prospective, randomized, controlled trial of the safety and efficacy of a ketoanalogue-supplemented, vegetarian, very low-protein diet $(\mathrm{KD} ; 0.3 \mathrm{~g} / \mathrm{kg}$ vegetable proteins and 1 cps/5 kg ketoanalogues per day) revealed the correction of metabolic abnormalities, no changes in nutritional parameters, and no adverse reactions in non-diabetic adults with stable eGFR $<30 \mathrm{~mL} / \mathrm{min}$ per $1.73 \mathrm{~m} 2$ [70]. The largest study addressing CKD, the Modification of Diet in Renal Disease (MDRD) Study, provided minimal results [71]. However, in this long-term study, compliance and therefore protein intake was problematic [72]. Follow up protein measurements were not taken, greatly reducing confidence in the outcome.

\section{Type I Diabetes - diabetic nephropathy}

Interventional studies show that a low protein vegetarian diet can slow the progression of chronic kidney disease in Type 1 diabetics and improve their clinical laboratory test results. According to a meta-analysis of five studies including a total of 108 patients, dietary protein restriction slowed the progression of diabetic nephropathy in patients with type 1 diabetes. [19] More recently, a 4-year randomized controlled trial with 82 patients, who had type 1 diabetes with progressive diabetic nephropathy, showed that a moderately low-protein diet $(0.9 \mathrm{~g} /$ $\mathrm{kg} /$ day) reduced the risk of end-stage renal disease or death by $76 \%$, although no effect on GFR decline was observed [73]. The mechanisms by which a low-protein diet may reduce progression of diabetic nephropathy are still unknown but might be related to improved lipid profile and/or glomerular hemodynamics.

Another study specifically looked at the effect of a vegetarian low-protein, low phosphorous diet on patients with diabetic nephropathy secondary to type I diabetes. The diet used provided $0.3 \mathrm{gm} / \mathrm{Kg} /$ day protein, no more than $3.5 \mathrm{mg} / \mathrm{Kg} /$ day phosphorus, and $60 \%$ of the calories were from carbohydrate. The sodium and potassium contents were 0.3 and $1.1 \mathrm{mmol} / \mathrm{Kg} /$ day respectively. The diet was also supplemented with a mixture of keto amino acid analogues and essential amino acids 126mg/ $\mathrm{Kg} /$ day, CaCO3 3-6gm/day, and a multivitamin with iron [74]. This study showed that a supplemented vegetarian diet in type I diabetes patients with overt nephropathy resulted in a slowing or even arrest of the progression of renal failure. Despite the increased carbohydrate, there was no need to increase the dose of insulin and in some patients the dose was decreased. The diet also reduced proteinuria and serum urea [74].

\section{CKD in Pregnancy}

Using the most recent classification system, 3\% of women of childbearing age are affected by CKD $[75,76]$. For these women, the risk of an adverse pregnancy rises very significantly, even in stage 1 [77]. Despite vast improvements in fetal outcomes, pregnancy in women with CKD is fraught with hazards; worsening renal function and complications such as preeclampsia and premature delivery are common [78]. During the pregnancy of a patient with CKD, the amount of protein in the diet must be balanced between the goal of diminishing hyperfiltration and increasing metabolic needs of pregnancy [25] Due to the fact that pregnancy induces hyperfiltration, diets with restricted amount of protein should be beneficial in this group of patients $[79,80]$. Vegan or vegetarian supplemented low-protein diets in pregnant women with stages 3-5 CKD reduce the risk of small-for-gestational-age babies, without detrimental effects on kidney function or proteinuria in the mother [81].

CKD during pregnancy presents a clinical challenge, especially considering the paucity of therapeutic tools available in pregnant women. One study investigated the feasibility of supplemented vegetarian low-protein diets in pregnancy, as a "rescue treatment" for severe CKD and or proteinuria [79] None of the 11 patients needed renal replacement therapy within the 6 months before delivery. No patient complained of side effects, nor developed hyperkalemia or hypercalcaemia. All babies were well at 1-month post-delivery, and 7.5 years later [79]. A supplemented vegetarian low-protein diet (0.6-0.7 g/ $\mathrm{kg}$ per day) turned out to be sufficient for the maintenance of satisfactory nutritional status during the pregnancy and after delivery, even in breast-feeding women [48]. 
For pregnant women with focal segmental glomerulosclerosis, a study showed that a moderately protein restricted, keto analogue supplemented, plant-based diet helped control proteinuria [82]. Another study reviewed the results obtained over 15 years of treating pregnant women with CKD on moderately restricted plant-based low-protein diets. It confirms that such a diet is a safe option in the management of pregnant CKD patients [83] A trend towards better preserved fetal growth was observed. These results indicate that the treatment of pregnant CKD women on moderately restricted plant-based lowprotein diet is a safe option in the management of pregnant CKD.

\section{Acidosis}

Metabolic acidosis is a common complication of chronic kidney disease. The frequency of metabolic acidosis increases along with the decrease of renal function, especially when the glomerular filtration rate falls below $30-40 \mathrm{~mL} / \mathrm{min} / 1.73$ $\mathrm{m} 2$ [84-86]. The most common negative consequences are as follows: bone demineralization, [87] tubulointerstitial fibrosis, $[88,89]$ inflammation, [90] the stimulation of the reninangiotensin system [91] and adrenocortiocotrophic hormone [92]. According to studies, metabolic acidosis is also associated with increased cardiovascular risk [93-97].

Mechanisms by which metabolic acidosis may stimulate nephropathy progression in CKD involve sustained, high levels of mediators of increased distal nephron acidification in response to GFR reduction, such as endothelin and aldosterone [98] In CKD patients, low bicarbonate reflects primary metabolic acidosis, [99] and it is considered to be a risk factor for mortality and CKD progression [100-103]. Growing evidence suggests that the source of protein (plant or animal) may be more important than the quantity of protein consumed. Meat produces more of a dietary acid load (DAL) than plant foods. A typical diet in industrialized countries produces acid of about $1 \mathrm{mEq} / \mathrm{kg} /$ day. However, it is reduced by more than one third among vegetarians and is close to neutrality among vegans [104]. Another study showed that higher levels of DAL were associated with 3.04 times higher risk of ESRD in the highest versus lowest tertial [105].

The fact that the acid load linked to animal proteins is higher than that linked to plant proteins is already known in the scientific community $[105,106,38]$. Moe et al. showed that the use of only plant proteins, compared to animal proteins, was able to reduce daily serum and urinary phosphate levels in eight subjects, the load of sodium, calcium and phosphorus being equal $[14,49]$. One reason for this is the tendency for excess meat intake to disrupt the acid base balance, since protein derived from animal sources contains acid-forming substances such as sulfur-containing amino acids and phosphorus, in addition to the excessive protein load. Sulfur-containing amino acids, when oxidized, generate sulphate, a non-metabolizable anion that contributes to total body acid load [37,97,107]. Protein from plant sources contains higher levels of glutamate, an anionic amino acid that upon metabolism consumes hydrogen ions to remain neutral, thereby reducing acidity levels [107,97,37]. Plant foods are also generally higher in anionic potassium salts, which also result in the consumption of hydrogen ions upon metabolism and thus reducing acid load $[37,97,107]$.

In response to an increase in acid load, the kidney adapts by increasing ammonium ion excretion in order to expel excess hydrogen ions, therefore increasing the demand for ammonia production [108]. This stimulates the breakdown of glutamine and other amino acids, promoting protein catabolism and muscle wasting [109] while also leading to renal hypertrophy [110]. Metabolic acidosis also promotes protein muscle wasting via the activation of the ATP-dependent ubiquitin proteasome system [111]. In response to a high acid load, the kidney also undergoes functional changes, including promotion of glomerular hyperfiltration and renal vasodilation, features typical of early diabetic kidney disease $[37,97,107]$.

Current guidelines recommend treatment with alkali when bicarbonate levels are lower than $22 \mathrm{mMol} / \mathrm{L}$, [84] to prevent complications, such as insulin resistance, [112-114] cardiovascular diseases and progression of CKD, among others [96,114]. The Kidney Disease Outcomes Quality Initiative (KDOQI) recommends $\mathrm{Na}+$ citrate or $\mathrm{NaHCO} 3$ in the treatment of metabolic acidosis in CKD [115]. However, $\mathrm{Na}+\mathrm{Na}+$ citrate and NaHCO3 may aggravate volume retention and/or hypertension in CKD [107].

A correction of metabolic acidosis can also be achieved with a diet rich in fruit and vegetables, $[4,37,47,116-122]$. as well as with a very low-protein vegetarian diet [107]. A plantbased diet was shown to influence survival through its effect on metabolic acidosis [118]. Results from the Chronic Renal Insufficiency Cohort Study suggest that consumption of a greater proportion of protein from plant sources is associated with higher bicarbonate levels, as well as an improved phosphorous balance in patients with CKD [123]. A case-control study by Di Iorio et al. [107] clearly demonstrated that a very low-protein diet (VLPD) containing a high quantity of fruit and vegetables, with a very low amount of protein, supplemented with essential amino acids and ketoanalogs of non-essential amino acids, reduced net endogenous acid production (NEAP) by $53 \%$ after six months and $67 \%$ after 12 months, and potential renal acid load (PRAL) by $120 \%$ after six months and $138 \%$ after 12 months. Also, the correction of hyperpotassemia, as a consequence of a physiological correction of metabolic acidosis, was observed after 12 months on the VLPD diet [107]. A study by Bellasi et al. [93] indicated the relationship between metabolic acidosis and insulin resistance in diabetic patients with chronic kidney disease. They also showed that oral sodium bicarbonate administration or a low-protein vegetarian diet rich in fruit and vegetables, prescribed to avoid or correct metabolic acidosis, improved insulin sensitivity in the CKD plus diabetes mellitus (DM) population [93]. 
A study of stage 3 CKD patients showed an increase of bicarbonate levels by increasing the amount fruits and vegetables in their diet [47]. A one-year study of either added fruits and vegetables or sodium bicarbonate in individuals with stage 4 CKD, yielded an equal eGFR (estimated glomerular filtration rate) in both cases. It was associated with higher-than-baseline plasma total, and lower-than-baseline urine indices of kidney injury. The data indicated that fruits and vegetables improved metabolic acidosis and reduced kidney injury in stage 4 CKD without producing hyperkalemia [37].

\section{0mega-6 fatty acids}

Recent studies suggest additional potential benefits of healthy eating on CKD progression. Individuals consuming too much saturated fat are more likely to progress to CKD [124]. Growing evidence suggests the potential benefit of dietary fat modification strategies in CKD patients, including increasing the amount of linoleic acid (n-6 PUFA) from vegetable oils and thus reducing the amount of saturated fat ingested. $[125,126]$. The best way to do this is to reduce the consumption of animal products which are high in saturated fat, and to increase the number of nuts and seeds which are rich in linoleic acid. No studies have yet shown a benefit from increasing Omega-3 fatty acids for CKD patients.

\section{The Nephrotoxic effects of persistent organic pollut- ants}

The impact of environmental chemicals on public health and clinical well-being has long been recognized, with a historical focus on heavy metals and molecules that are produced in the work place. Increasing data have, however, indicated that the general public is exposed to a wide range of chemicals as a consequence of normal consumer activities. These activities include dietary intake of food $[127,128]$. Numerous reports have documented toxicity that occurs in response to graded exposure to a wide range of environmental chemicals. Persistent organic pollutants (POPs) are synthetic organic chemicals such as dioxins, furans, polychlorinated biphenyls (PCBs), and organochlorine pesticides -chemicals mainly created by industrial and agrichemical activities either intentionally or as by-products - that have an intrinsic resistance to natural degradation processes and are therefore environmentally persistent and bio-accumulate through the food chain, increasing greatly in concentration at each subsequent trophic level [129]. POPs accumulate in adipose tissue of animals as well as humans. Thus, the majority of human exposure to persistent organic pollutants occurs as a result of eating foods containing meat, milk, eggs and fish due to accumulation of POPs in animal fat $[130,131]$.

Polychlorinated dibenzo-p-dioxins (PCDDs), dibenzofurans (PCDFs), and polychlorinated biphenyls (PCBs) are lipophilic and can persist in the body for years [132]. An individual's body burden is a product of multiple years of exposure and a lifetime of varying elimination rates. Different congeners of PCDDs, PCDFs, and PCBs each have different levels of persistence in the human body, reflected in their different reported half-lives. In human adipose tissue, they may represent a pool of toxicants with diverse health effects including carcinogenesis and renal damage [133].

The kidney, because of its high rate of perfusion, active transport capabilities, and concentrating functions, is often exposed to much higher concentrations of chemicals than are other organs. These high concentrations may cause toxic effects to the kidney [134]. Emerging data suggest that the kidney is an important site of injury after chemical exposure with POPs $[130,131]$. Prolonged cumulative lifetime exposure to certain POPs, in conjunction with age-associated decline in kidney function and other comorbid conditions, may accelerate the rate of deterioration in kidney function and progression to CKD $[130,131]$. Exposure to persistent organic pollutants are a very strong risk factor for type 2 diabetes [60]. Since the kidneys function to remove waste products from the blood, diabetic nephropathy could partly be either the cause or the consequence (or both) of exposure to dioxins, furans and dioxin-like PCBs [131]. One study examined the association of agricultural persistent organic pollutants including six organochlorine pesticides and pesticide metabolites in human blood. When p,p'-DDT and heptachlor epoxide were both elevated, the odds ratio for diabetic nephropathy was 2.76 times the average. When six of six organochlorine pesticides and pesticide metabolites, were elevated, the odds ratio for diabetic nephropathy was 3.00 $[134,135]$.

Another study assessed the association of persistent organic pollutants from industrial processes including 6 chlorinated dibenzo-p-dioxins, 9 chlorinated dibenzofurans and 8 polychlorinated biphenyls (PCBs) in blood with diabetic nephropathy (defined as urinary albumin to creatinine ratio $>30 \mathrm{mg} / \mathrm{g}$ ) in diabetics as defined by a glycated hemoglobin of $>6.5 \%$. When 4 or more of the 23 chemicals were elevated the risk for diabetic nephropathy was 7 times higher than otherwise [131]. PCDDs and PCDFs are readily absorbed through the digestive tract, which is enhanced through the ingestion of fatty foods. The lipophilic characteristics of PCDDs and PCDFs allows for slow excretion in bile and urine, $[131,136]$. Thus, prolonging the exposure of kidney and colon cells to these toxins.

PCB metabolism primarily occurs in the liver, where it must first be hydroxylated to increase the polarity of the molecule, before it is excreted in the bile [137]. The rate of metabolism varies depending on the degree of chlorination of the congener [138]. Metabolism of PCBs can also produce toxicologically active agents, such as arene oxides that must be enzymatically detoxified and excreted, and/or can form toxic adducts which can damage the kidney cells' DNA [139]. Dioxins metabolism also takes place in the liver. Metabolites are excreted through the biliary fecal route. The half-life of dioxins can be up to several decades, due 
to enterohepatic recirculation. The effects of dioxins are chiefly mediated by the aryl hydrocarbon receptor (AHR), a ligandactivated transcription factor that regulates gene expression [136]. Studies have shown that those exposed to the greatest amount of toxins have reduced renal function. Compared to the lowest quartile, the highest quartile of toxin exposure resulted in a $14.8 \mathrm{ml} / \mathrm{min} / 1.73 \mathrm{~m} 2$ and a $21.5 \mathrm{ml} / \mathrm{min} / 1.73 \mathrm{~m} 2$ reduction in estimated GFR in men and women, respectively $[131,136]$. This decrease in GFR must be distinguished from the lower GFRs that healthy vegans have, that are a consequence of healthy kidneys.

The risk of hyperuricemia was higher for higher serum concentrations of organochlorine pesticides, PCDDs, and dioxin-like substances raising the risk of uremia by $1.4,1.3$, and 2.4 respectively $[131,136,140]$. Even adults with only lowlevel exposure to dioxins are also still at heightened risk of hyperuricaemia. The increase in risk of hyperuricemia ranged from 2.3 to 3.0, depending upon the specific dioxin congener exposure $[131,136,140]$.

\section{Bacterial Toxicology}

Uremic retention molecules (URMs), contributing to the syndrome of uremia, may be classified according to their site of origin, that is, endogenous metabolism, microbial metabolism, or exogenous intake. It is increasingly recognized that bacterial metabolites, such as phenols, indoles, and amines, may contribute to uremic toxicity. In vitro studies have implicated bacterial URMs in CKD progression, cardiovascular disease, and bone and mineral disorders. Furthermore, several observational studies have demonstrated a link between serum levels of bacterial URMs and clinical outcomes. Bacterial metabolism may therefore be an important therapeutic target in CKD. There is evidence that reduced renal clearance, increased colonic generation and absorption explain the high levels of bacterial URMs in CKD [141].

The microbial metabolism of protein also produces a number of metabolites that may negatively affect the kidneys $[142,143]$. Indoxyl sulfate (IS) and p-cresyl sulfate (PCS) are uremic toxins derived solely from colonic bacterial fermentation of protein. [142-144]. Circulating indoxyl sulphate can increase oxidative stress in the renal tubular cells and the glomeruli $[145,143]$. Also, in-vitro indoxyl sulphate has been observed to activate inflammatory pathways resulting in an increase in the expression of monocyte chemoattractant protein-1 (MCP-1) and intracellular adhesion molecule-1 (ICAM-1) [146]. P-cresyl sulfate has similarly been linked to CKD and CVD mortality, although the mechanism is not yet as well defined $[147,148]$.

Interestingly, it has been noted that vegetarians have lower levels of these nephrotoxic compounds compared with omnivores, in both healthy [149] and CKD populations [150] Vegetarians tend to have higher fiber intakes, [147] which could be metabolized by the colonic microbiota instead of amino acids, leading to a reduction in indoxyl sulphate and p-cresyl sulfate.
This provides another mechanism to explain why vegetarian protein sources appear less detrimental than animal protein sources. Furthermore, carnitine and lecithin present in red meat are metabolized by the microbiota to form trimethylamine- $\mathrm{N}$ oxide, [151] which has been linked to cardiovascular events. The interaction between animal sources of protein and gut bacteria in CKD warrants further investigation.

Determining an optimum protein to fiber ratio could allow for appropriate protein intake to prevent protein energy wasting, without adverse effects on renal outcomes [143]. Not only do vegetarian proteins carry an advantage, but vegetarians themselves produce less sulphate and p-cresyl sulfate. In one study comparing healthy vegetarian to non-vegetarians, the average PCS excretion was $62 \%$ lower and average IS excretion was 58\% lower in vegetarians, compared to participants consuming an unrestricted diet [150]. In the same study vegetarian patients undergoing hemodiafiltration also had lower levels of Indoxyl sulfate and p-cresyl sulfate [150].

Treatment of ESRD is now focused on removing uremic solutes by dialysis. In theory, treatments that reduce solute production could also reduce solute levels and ameliorate uremic illness [149]. Over the long term, vegetarian and unrestricted diets may influence PCS and IS production by altering the colon microbial flora, or microbiome, as well as by providing different nutrients to colon microbes on a day-to-day basis. [149]. Dietary fiber was considered as a treatment for chronic renal failure more than 30 years ago, where it was found to reduce plasma urea [152]. Interventions that have focused on increasing total dietary fiber intake in patients with pre-dialysis CKD have reported reductions in serum creatinine levels [153] and plasma p-cresol [154]. A four-week study in which patients with chronic renal failure consumed 50 grams per day of acacia gum, a highly fermentable fiber, led to a mean reduction in plasma urea of $12 \%$ [155]. In another study, supplementation with acacia gum for three months led to decreases in serum urea, creatinine and phosphate by $31 \%, 10 \%$ and $22 \%$, respectively [156].

Recently, several short-term studies have been undertaken using non-digestible carbohydrates in patients receiving dialysis. A four-week Belgian study in haemodialysis patients showed that plasma p-cresyl sulfate decreased by $20 \%$ when supplemented with oligofructose-enriched inulin [157]. This result has been echoed in a similar study that combined galactooligosaccharides with probiotics [158] While neither of these studies showed a reduction in indoxyl sulphate, a recent sixweek dietary intervention with resistant starch in haemodialysis patients led to a mean reduction of plasma indoxyl sulphate and p-cresyl sulfate by $29 \%$ and $28 \%$, respectively [159].

Some guidelines for the management of CKD make no mention to the role of non-digestible carbohydrates, which some researchers feel should be rectified on the basis of emerging evidence [160]. Dietary fiber intake is about 20\%-30\% lower in 
haemodialysis patients compared to control subjects, $[161,162]$ with dialysis patients consuming approximately $11 \mathrm{~g} /$ day dietary fiber, significantly less than the recommendation of $25 \mathrm{~g} /$ day [163]. These data suggest that non-digestible carbohydrates are effective at improving biochemical markers in haemodialysis patients, and that dietary interventions involving these compounds may be particularly relevant given the low intakes seen in this population. The use of dietary fiber supplementation is a simple, non-invasive option that does not negatively impact patients' quality of life $[25,143,164]$.

\section{Phosphorus}

In patients with chronic kidney disease, high dietary phosphorus burden may worsen hyperparathyroidism and renal osteodystrophy, promote vascular calcification and cardiovascular events, and increase mortality. In addition to the absolute amount of dietary phosphorus, its type (organic versus inorganic), source (animal- versus plant-derived), and ratio to dietary protein may be important. Organic phosphorous in plant foods such as seeds and legumes are less bioavailable because of limited gastrointestinal absorption [165].

Table 1: Bioavailability of phosphorus from various food sources.

\begin{tabular}{|c|c|c|}
\hline Food Source & $\begin{array}{c}\text { Bioavailability of } \\
\text { Phosphorus }\end{array}$ & References \\
\hline Plant sources & $20-40 \%$ & {$[168,169,170]$} \\
\hline Dairy products & $30-60 \%$ & {$[165,167,168]$} \\
\hline Meat products & Up to $80 \%$ & {$[165,167,168]$} \\
\hline $\begin{array}{c}\text { Inorganic phosphate } \\
\text { additives }\end{array}$ & $90-100 \%$ & {$[171]$} \\
\hline $\begin{array}{c}\text { Phosphoric acid in } \\
\text { cola drinks }\end{array}$ & $100 \%$ & {$[158]$} \\
\hline
\end{tabular}

Disturbances in mineral metabolism are common complications of chronic kidney disease (CKD), beginning at approximately CKD stage 3 and 4. Patients with advanced chronic kidney disease maintain a positive phosphorus balance through phosphaturia. The damaged kidney is unable to fully excrete a phosphorus load, which leads to compensatory secondary hyperparathyroidism and elevations in fibroblast growth factor 23 (FGF23) in an attempt to increase urinary phosphorus excretion to maintain phosphorus balance. [165,166]. This provides the rationale for recommendations to restrict dietary phosphate intake to $800 \mathrm{mg} / \mathrm{d}$. Protein-rich foods such as legumes, meat, poultry, fish, eggs and dairy products are the main sources of organic phosphate. A strong positive correlation between dietary protein from animals and phosphorous intake is responsible for the frequent association of high protein intake in the diet with excessive ingestion of phosphorous, and the resulting hyperphosphatemia in people with CKD [65, 152]. However, the protein source of the phosphate is important, as a high protein (and high phosphorus) diet does not always translate to increased serum phosphate levels [167-171]. The bioavailability of organic phosphate varies depending on the food source (Table 1)
The difference in phosphorus bioavailability between meat and plant protein sources may partially explain the benefits of consuming a greater proportion of protein from plants sources, as described above. Phosphate absorption is linearly related to phosphate intake, with bioavailability being the major determining factor in phosphate uptake from the diet [172]. Thus, for organic phosphate, food choices can make a significant difference in the amount of phosphate that is absorbed from the diet. Inorganic phosphorous may be added to foods in the form of additives, which are typically used to improve taste, texture, shelf life or processing time [173]. These additives are primarily inorganic phosphate salts that require no enzymatic digestion and dissociate rapidly in the low $\mathrm{pH}$ environment of the stomach. The phosphoric acid in cola drinks has a bioavailability of $100 \%$ [158]. These foods should therefore be avoided. In one inpatient study, the results indicated that 1 week on a vegetarian diet led to lower serum phosphorus levels and decreased FGF23 levels [166].

\section{The use of soy protein}

The type of protein consumed affects alterations in kidneyrelated biomarkers in CKD patients. One study sought to assess the effects of soy protein consumption on renal related markers among type 2 diabetic patients with nephropathy. A randomized clinical trial was conducted with one diet containing $0.8 \mathrm{~g} / \mathrm{kg}$ protein (70\% animal and $30 \%$ vegetable proteins), and a similar diet contained the same amount of protein with $35 \%$ animal protein, $35 \%$ soy protein, and $30 \%$ other vegetable proteins. Consumption of soy protein reduced urinary urea nitrogen, proteinuria, blood sodium), and serum phosphorus compared with animal protein consumption [174].

A meta study of 12 CKD studies showed that dietary soy resulted in a significant decrease in serum creatinine, phosphorous, CRP and proteinuria in predialytic patients. The study also found that soy protein intake could maintain the nutritional status in dialysis patients, though no significant change in CRP, BUN, and serum phosphorus was detected [175]. Another study found that a diet with a higher proportion of protein from plant sources, primarily soy, is associated with lower mortality in those with eGFR $<60 \mathrm{~mL} / \mathrm{min} / 1.73 \mathrm{~m} 2$ of $23 \%$ Therefore, at a given total protein intake, a higher proportion of dietary protein from plant sources such as soy is associated with lower mortality risk in chronic kidney disease [176]. These studies show that soy, a popular and readily available source of plant-based protein, is an effective choice for treating CKD patients.

\section{Cardiovascular disease and hypertension}

Cardiovascular disease remains a major cause of morbidity and mortality in patients with chronic kidney disease (CKD), accounting for approximately $50 \%$ of all deaths in patients on dialysis and in recipients of renal transplants [177]. Recentstudies have demonstrated that modification of the dietary pattern by 
reducing animal protein intake and increasing consumption of plant-based foods could influence cardiovascular risk profile and mortality rate. Moreover, phosphate bioavailability from plant proteins is reduced. These effects lead to some benefits for chronic kidney disease (CKD) patients [178].

The vegan diet, known for its better lipoprotein profile and antioxidant content, can protect against CVD. One study compared patients with advanced chronic kidney disease on a conventional low-protein diet with those on a ketoanalogue supplemented vegan diet. Patients on a vegan diet showed increased HDL cholesterol levels with a reduction of LDL cholesterol and an increase of apoA1/apoB ratio. A significant reduction of total homocysteine, $\mathrm{Lp}(\mathrm{a})$ and CRP levels were also observed in vegan patients [179]. Dialysis patients have both traditional and nontraditional risk factors for cardiovascular disease, including the retention of advanced glycation end products (AGE). In one study, skin auto fluorescence (SAF), a marker of tissue AGE deposition, was reduced in vegetarian hemodialysis patients compared to patients on a conventional chronic kidney disease diet. This study showed that a vegetarian diet may reduce exposure to preformed dietary AGE thus reducing their risk of CVD [180].

A study comparing a vegan diet to the more conventional low and very low-protein diet found that vitamin K1, fiber content, and the alkalizing potential were all better on a vegan diet than the other diets. The net endogenous acid production decreased the most, and the same finding occurred for the potential renal acid load (PRAL). These features may have favorable effects on Vitamin K1 status, intestinal microbiota and acid-base balance. Thus, the vegan diet also has beneficial effects on vascular calcification and bone disease, on protein metabolism, on colonic environment and circulating levels of microbial derived uremic toxins [181]. The low-protein and phosphorus intake has a crucial role for reducing proteinuria and preventing and reversing hyperphosphatemia and secondary hyperparathyroidism, which are major causes of the vascular calcifications, cardiac damage, and mortality risk of uremic patients.

The reduction of nitrogenous waste products and lowering of serum PTH levels may also help ameliorate insulin sensitivity and metabolic control in diabetic patients, as well as increase the responsiveness to erythropoietin therapy, thus allowing greater control of anemia. Vegetarian diets may have also antiinflammatory and antioxidant properties. Proper nutritional treatment early in the course of renal disease may be useful to reduce the cardiovascular risk in the renal patient [182]. In one study patients were examined for triglycerides (TG), total cholesterol, HDL and LDL cholesterol, and apolipoproteins Apo A1, Apo B, and Lp(a). Lipid peroxidation (LP) has recently been suggested to trigger the atherosclerotic process as well as to worsen the progression of renal disease. Autoantibodies against oxidized low-density lipoproteins (Ox-LDLAb) were considered to provide a sensitive marker to detect LDL oxidation in vivo.
This study shows that the vegan diet, by reducing LP, total cholesterol, TG, and Lp(a), decreases the risk of cardiovascular disease and is worth being considered as an alternative effective therapeutic tool in patients with advanced CKD [183].

In another study of CKD patients, Lp(a) concentrations increased with the progression of renal failure, and a significant correlation was observed with serum creatinine (sCr). Despite the elevated sCr levels, patients on a keto analogue supplemented vegetarian diet had an almost normal Lp(a) concentration while only $15 \%$ of the reference group had [184]. Elevated blood pressure (BP) is one of the most frequent complications of chronic kidney disease [185]. Its correction is an important intervention because uncontrolled hypertension is a recognized determinant of progression of renal damage [186-189]. It also represents a major cause for the elevated cardiovascular morbidity and mortality detected in these patients [190-193]. Accordingly, current clinical practice guidelines strongly suggest reducing BP to less than $130 / 80 \mathrm{mmHg}$ [194]. One study of stage 4 and 5 patients on a very low-protein ketoanalogue supplemented diet, where the protein was mostly plant protein, showed an average decrease in blood pressure from 143/84 to $128 / 78$. The benefit of the mostly vegetable protein diet was observed, even in patients who started with inadequate BP control at baseline in spite of multidrug antihypertensive therapy [195]. Other studies have shown that vegetarian diets are associated with lower blood pressure [196-199]. A recent study showed that a vegan diet was associated with lower blood pressure in asymptomatic participants with proteinuria [200]. This diet could be a nonpharmacologic method to reduce blood pressure and help prevent chronic kidney disease.

\section{Clinical Considerations}

Several studies have determined the nutritional safety of plant-based diets in CKD patients, despite dietary protein restriction. Plant- based diets are associated with a reduced risk of all-cause mortality in CKD patients. Studies confirm a kidney protective effect of plant-based diets in the primary prevention of CKD and the secondary prevention of CKD progression [201].

Dietary therapy has to be deeply analyzed, and nutritional prescription has to be focused not only on reduction of protein content but also on proteins' quality [4,37,38,105-107]. Adherence to diet, fluids and dialysis are the cornerstone of renal failure treatment [202]. Extensive changes to food and lifestyle are required for patients with CKD. Many diet components must be monitored such as calories, protein, sodium, potassium, calcium, phosphorus, and fluid [203]. No single educational or clinical strategy has been shown to be consistently effective across CKD populations. Highest adherence has been observed when both diet and education efforts are individualized to each patient and adapted over time to changing lifestyle and CKD variables [204]. Factors such as taste, convenience and the impact of the diet on social eating occasions are also important in enhancing dietary adherence [205]. 
The education focus may be more effective by addressing one opportunity at a time, rather than a broad long-term diet planning strategy [204]. Social support is especially important for both hemodialysis and peritoneal dialysis patients in terms of greater satisfaction and quality of life and fewer hospitalizations. Intervention studies to possibly improve these outcomes are warranted [206]. A regimen with $0.6 \mathrm{~g} / \mathrm{kg} /$ day of proteins is often difficult for a patient to maintain unless a vegan diet (usually supplemented with keto acids) has been recommended. To take the protein level even lower, 'non-proteic' (commercially available) carbohydrates can be added. The combination of both approaches allows protein intakes as low as $0.3 \mathrm{~g} / \mathrm{kg} /$ day [3]. In a 4-year study by Piccoli, implementation was aimed at testing a simplified approach to a plant-based low-protein diet (protein intake of $0.6 \mathrm{~g} / \mathrm{kg} /$ day) in patients with severe or progressive CKD, who had been referred to a new nephrology unit. In this study, flexibility started from the prescription, as the diet was simply based on allowed and forbidden foods, without the need to weigh all foods. Occasional free choice meals were allowed to reduce the psychological burden [3]. This method achieved positive results, while providing a simpler regimen for patients. Supplementation of a VLPD with ketoanalogues seems to have some advantages above and beyond the protein restriction. If enough energy is provided, ketoanalogues could be converted to essential amino acids by urea recycling, allowing for a nutritionally safe, more severe reduction in protein intake $[41,43]$. Furthermore, the calcium content of ketoanalogue preparations and their phosphate binder capabilities allow for even better correction of mineral metabolic abnormalities $[41,44]$.

It is noteworthy that educational level (often associated with higher compliance), diabetes, overall comorbidity (often associated with poor dietary compliance) and old age (frequently considered to impair efficient modulation of the diet) were not confirmed as strong relevant factors in attaining the medium term follow up goals of this diet [3].

In this study, the diet was initially prescribed as a one-month trial and was prescribed and managed by the nephrologist in the context of the routine clinical follow up. Interestingly, in stable patients with at least 6 months of follow up, compliance was impressive, with a median protein intake of $0.5 \mathrm{~g} / \mathrm{kg} /$ day. This supports the hypothesis that subtle personal preferences, as well as clear motivations, are fundamental in the relationship with food and diet. Therefore, the authors conclude, this diet should be proposed to all patients without preclusion [3]. The CKD patient often presents with other chronic diseases such as hypercholesterolemia, [207] coronary artery disease, [208,209] and type 2 diabetes [60]. The plant-based diet is useful for treating these comorbid diseases as well. Clinical parameters should be monitored, and medications adjusted as the treatment effect becomes evident.

\section{Discussion}

The overall prevalence of chronic kidney disease in the general population is approximately 14 percent. Medicare spending for patients with CKD ages 65 and older exceeded $\$ 50$ billion in 2013 and represented 20 percent of all Medicare spending in this age group. Given that the plant-based diet reduces the risk of chronic kidney disease in the first place, it would seem to be a very valuable prophylaxis. At least three main reasons suggest that the time is ripe for a systematic integration of a vegetarian diet into the clinical treatment of CKD: the cost of dialysis, the clinical advantages and the failure of early dialysis to prolong survival [3]. CKD is a challenging disease to treat for both patient and physician. There are many clinical variables to be simultaneously managed. Complicating treatment even further is that treatment often needs to be modified as the disease progresses. The plant-based diet can treat phosphotemia, uremia, acidosis, proteinuria, acidosis and intestinal dysbiosis, and can help prevent chronic kidney disease from advancing to end stage renal disease. Almost half of individuals with CKD also have diabetes and/or self-reported cardiovascular disease. CKD often occurs in the context of multiple comorbidities and has been termed a "disease multiplier" [210]. The plant-based diet helps prevent type 2 diabetes, as well as treat it even more effectively than the leading medication, Metformin. It can also help prevent and treat coronary artery disease, the leading cause of mortality in chronic kidney disease. The plant-based diet has no contraindications or adverse reactions. It reduces health care costs for both the patient and society. Low-protein plant-based diets do not result in malnutrition or hyperkalemia and are even safe in pregnancy. It may also be possible to raise the amount of protein in the diet, if the protein is plant-derived. Supplementation with ketoanalogues make the treatment more efficacious. Plant-based diets are no longer very unusual as they have become more popular in the general population in recent years. Given all of the benefits, the plant-based diet deserves a place among the physician's treatment options for CKD.

\section{References}

1. Berger A, Edelsberg J, Inglese G, Bhattacharyya S, Oster G (2009) Cost comparison of peritoneal dialysis versus hemodialysis in end-stage renal disease. Am J Manag Care 15(8): 509-518.

2. Meguid El Nahas A, Bello A (2005) Chronic kidney disease: the global challenge. Lancet 365(9456): 331-340.

3. Piccoli G, Ferraresi M, Deagostini M, Vigotti F, Consiglio V, et al. (2013) Vegetarian low-protein diets supplemented with keto analogues: a niche for the few or an option for many? Nephrol Dial Transplant 28(9): 2295-2305.

4. Goraya N, Wesson D (2016) Dietary Protein as Kidney Protection: Quality or Quantity? J Am Soc Nephrol 27(7): 1877-1879.

5. Murray C, Atkinson C, Bhalla K, Birbeck G, Burstein R, et al. (2013) The State of US Health, 1990-2010 Burden of Diseases, Injuries, and Risk Factors. JAMA 310(6): 591-606.

6. Beale LS (1869) Kidney Diseases, Urinary Deposits and Calculous Disorders, Their Nature and Treatment. Third Edition ed. London: John Churchill and Sons. 
7. Giordano C, Madias M (1982) Protein restriction in chronic renal failure. Kidney International. 22(4): 401-408.

8. Lewis D (1921) On the Influence of a Diet with High Protein Content on the Kidney. Can Med Assoc J 11(9): 682-683.

9. Addis T, Lew W (1939) Diet and death in acute uremia. J Clin Invest 18(6): 773-775.

10. Addis T (1949) Glomerular nephritis: Diagnosis and treatment London, UK: Macmillan 309(6968): 1557-1563.

11. Piccoli G (2010) Patient-based continuum of care in nephrology: why read Thomas Addis' “Glomerular Nephritis" in 2010? J Nephro 23(2) 164-167.

12. Borst J (1948) Protein katabolism in uraemia; effects of protein-free diet, infections, and blood-transfusions. Lancet 1(6509): 824-829.

13. Thilly N (2013) Low-protein diet in chronic kidney disease: from questions of effectiveness to those of feasibility. Nephrol Dial Transplant 28(9): 2203-2205.

14. Giovannetti S, Maggiore Q (1964) A low-nitrogen diet with proteins of high biological value for severe chronic uraemia. Lancet 1(7341): 1000-1003.

15. Lafage M, Combe C, Fournier A, Aparicio M (1992) Ketodiet physiological calcium intake and native vitamin D improve renal osteodystrophy. Kidney Int 42(5): 1217-1225.

16. Rigalleau V, Combe C, Blanchetier V, Aubertin J, Aparicio M, et.al (1997) Low protein diet in uremia: effects on glucose metabolism and energy production rate. Kidney Int 51(4): 1222-1227.

17. Bernard S, Fouque D, Laville M, Zech P (1996) Effects of low-protein diet supplemented with ketoacids on plasma lipids in adult chronic renal failure. Miner Electrolyte Metab 22(1-3): 143-146.

18. Goraya N, Simoni J, Jo C, Wesson D (2012) Dietary acid reduction with fruits and vegetables or bicarbonate attenuates kidney injury in patients with a moderately reduced glomerular filtration rate due to hypertensive nephropathy. Kidney Int 81(1): 86-93.

19. Pedrini M, Levey A, Lau J, Chalmers T, Wang P (1996) The Effect of Dietary Protein Restriction on the Progression of Diabetic and Nondiabetic Renal Diseases: A Meta-Analysis. Ann Intern Med 124(7): 627-632.

20. Fouque D, Laville M, Boissel J, Chifflet R, Labeeuw M, et al. (1992) Controlled low protein diets in chronic renal insufficiency: metaanalysis. BMJ 304(6821): 216-220.

21. Fouque D, Laville M (2009) Low protein diets for chronic kidney disease in non-diabetic adults. Cochrane Database Syst Rev (3): CD001892.

22. Kasiske B, Lakatua J, Ma J, Louis T (1998) A meta-analysis of the effects of dietary protein restriction on the rate of decline in renal function. Am J Kidney Dis 31(6): 954-961.

23. (2002) Renal Dietitians Dietetic Practice Group National Renal Diet: Professional Guide. ( $2^{\text {nd }}$ edn). Chicago, Ill: The American Dietetic Association.

24. Garneata L, Stancu A, Dragomir D, Stefan G, Mircescu G (2016) Ketoanalogue-Supplemented Vegetarian Very Low-Protein Diet and CKD Progression. J Am Soc Nephrol 27(7): 2164-2176.

25. Gluba-Brzózka A, Franczyk B, Rysz J (2017) Vegetarian Diet in Chronic Kidney Disease-A Friend or Foe. Nutrients 9(4): E374.

26. Trevisan R, Dodesini A (2017) The hyperfiltering kidney in diabetes. Nephron 136(4): 277-280.

27. Wiseman M, Hunt R, Goodwin A, Gross J, Keen H, et al. (1987) Dietary Composition and Renal Function in healthy subjects. Nephron 46(1): 37-42.
28. Fraser GE (2009) Vegetarian diets: what do we know of their effects on common chronic diseases? Am J Clin Nutr 89(5): 1607S-1612S.

29. Burrows N, Hora I, Geiss L, Gregg E, Albright A (2017) Incidence of End-Stage Renal Disease Attributed to Diabetes Among Persons with Diagnosed Diabetes -United States and Puerto Rico, 2000-2014. MMWR Morb Mortal Wkly Rep. 66(43): 1165-1170.

30. Kazancioğlu R (2013) Risk factors for chronic kidney disease: an update. Kidney Int Suppl (2011). 3(4): 368-371.

31. Bosch J, Saccaggi A, Lauer A, Ronco C, Belledonne M, et al. (1983) Renal function reserve in humans. Effect of protein intake on glomerular filtration. Am J Med 75(6): 943-950.

32. Haring B, Selvin E, Liang M, Coresh J, Grams M, et al. (2017) Dietary Protein Sources and Risk for Incident Chronic Kidney Disease: Results from the Atherosclerosis Risk in Communities (ARIC) Study. J Ren Nutr 27(4): 233-242.

33. Lew Q, Jafar T, Koh H, Jin A, Chow K, et al. (2017) Red Meat Intake and Risk of ESRD. J Am Soc Nephrol 28(1): 304-312.

34. Lin J, Fung T, Hu F, Curhan G (2011) Association of dietary patterns with albuminuria and kidney function decline in older white women: a subgroup analysis from the Nurses' Health Study. Am J Kidney Dis 57(2): 245-254

35. Lin J, Judd S, Le A, Ard J, Newsome B, et al. (2010) Associations of dietary fat with albuminuria and kidney dysfunction. Am J Clin Nutr 92(4): 897-904.

36. Odermatt A (2011) The Western-style diet: a major risk factor for impaired kidney function and chronic kidney disease. Am J Physiol Renal Physiol 301(5): F919-F931.

37. Goraya N, Simoni J, Jo C, Wesson D (2013) A Comparison of Treating Metabolic Acidosis in CKD Stage 4 Hypertensive Kidney Disease with Fruits and Vegetables or Sodium Bicarbonate. Clin J Am Soc Nephrol 8(3): 371-381.

38. Gutiérrez O, Muntner P, Rizk D, McClellan W, Warnock D, et al. (2014) Dietary patterns and risk of death and progression to ESRD in individuals with CKD: A cohort study. Am J Kidney Dis 64(2): 204-213.

39. Kelly J, Palmer S, Wai S, Ruospo M, Carrero J, et al. (2017) Healthy Dietary Patterns and Risk of Mortality and ESRD in CKD: A MetaAnalysis of Cohort Studies. Clin J Am Soc Nephrol 12(2): 272-279.

40. Kontessis P, Jones S, Dodds R, Trevisan R, Nosadini R, et al. (1990) Renal, metabolic and hormonal responses to ingestion of animal and vegetable protein. Kidney Int 38(1): 136-144.

41. Chauveau P, Combe C, Rigalleau V, Vendrely B, Aparicio M (2007) Restricted protein diet is associated with decrease in proteinuria: Consequences on the progression of renal failure. J Ren Nutr 17(4): 250-257.

42. Ikizler T (2009) Dietary protein restriction in CKD: The debate continues. Am J Kidney Dis 53(2): 189-191.

43. Andrassy KM (2013) KDIGO CKD Guideline Development Work Group Members. KDIGO 2012 clinical practice guideline for the evaluation and management of chronic kidney disease. Kidney Int Suppl 3(1): 5-10.

44. Mitch W (1991) Dietary protein restriction in chronic renal failure: Nutritional efficacy, compliance, and progression of renal insufficiency. J Am Soc Nephrol 2(4): 823-831.

45. Malvy D, Maingourd C, Pengloan J, Bagros P, Nivet H (1999) Effects of severe protein restriction with ketoanalogues in advanced renal failure. J Am Coll Nutr 18(5): 481-486.

46. Gretz N, Meisinger E, Strauch M (1987) Influence of diet and underlying renal disease on the rate of progression of chronic renal failure. Infusionstherapie 14(Suppl 5): 21-25. 
47. Goraya N, Simoni J, Jo C, Wesson D (2014) Treatment of metabolic acidosis in patients with stage 3 chronic kidney disease with fruits and vegetables or oral bicarbonate reduces urine angiotensinogen and preserves glomerular filtration rate. Kidney Int 86(5): 1031-1038.

48. Zaldivar M, Peixoto A (2003) CKD series: cardiovascular risk reduction in patients with chronic kidney disease. Hosp Physician 39: 29-35, 50.

49. Anderson J (2008) Beneficial effects of soy protein consumption for renal function. Asia Pac J Clin Nutr 17(Suppl 1): 324-328.

50. Bernstein A, Treyzon L, Li Z (2007) Are high-protein, vegetable-based diets safe for kidney function: a review of the literature. J Am Diet Assoc 107(4): 644-50.

51. Ahmed F (1991) Effect of diet on progression of chronic renal disease. J Am Diet Assoc 91(10): 1266-1270.

52. Cupisti A, Ghiadoni L, D’Alessandro C, Kardasz I, Morelli E, et al. (2007) Soy protein diet improves endothelial dysfunction in renal transplant patients. Nephrol Dial Transplant 22(1): 229-234.

53. Elliott P, Stamler J, Dyer A, Appel L, Dennis B, et al. (2006) Association between protein intake and blood pressure: the INTERMAP Study. Arch Intern Med 166(1): 79-87.

54. Azadbakht L, Atabak S, Esmaillzadeh A (2008) Soy protein intake, cardiorenal indices, and $\mathrm{C}$ reactive protein in type II diabetes with nephropathy; a longitudinal randomized clinical trial. Diabetes Care 31(4): 648-654.

55. Anderson J, Blake J, Turner J, Smith B (1998) Effects of soy protein on renal function and proteinuria in patients with type 2 diabetes. Am J Clin Nutr 68(6 Suppl): 1347S-1353S.

56. Lohsiriwat S (2013) Protein diet and estimated glomerular filtration rate. Open J Nephrol 3(2): 97-100.

57. Barsotti G, Morelli E, Cupisti A, Meola M, Dani L, et al. (1996) A lownitrogen low-phosphorus Vegan diet for patients with chronic renal failure. Nephron 74(2): 390-394.

58. Wu T, Chang C, Hsu W, Wang I, Hsu C, et al. (2011) Nutritional status of vegetarians on maintenance haemodialysis. Nephrology (Carlton) 16(6): 582-587.

59. Jibani M, Bloodworth L, Foden E, Griffiths K, Galpin O (1991) Predominantly vegetarian diet in patients with incipient and early clinical diabetic nephropathy: Effects of albumin excretion rate and nutritional status. Diabet Med 8(10): 949-953.

60. Strombom A, Rose S (2017) The prevention and treatment of Type II Diabetes Mellitus with a plant-based diet. Endocrin Metab Int J 5(5): 00138.

61. Ogborn M, Bankovic-CN, Shoesmith C, Buist R, Peeling J (1998) Soy protein modification of rat polycystic kidney disease. Am J Physiol 274(3 Pt 2): F541-F549.

62. Trujillo J, Ramírez V, Pérez J, Torre-Villalvazo I, Torres N, et al. (2005) Renal protection by a soy diet in obese Zucker rats is associated with restoration of nitric oxide generation. Am J Physiol Renal Physiol 288(1): F108-F116.

63. Moe S, Chen N, Seifert M, Sinders R, Duan D, et al. (2009) A rat model of chronic kidney disease-mineral bone disorder. Kidney Int 75(2): 176184.

64. Mitch W, Remuzzi G (2016) Diets for patients with chronic kidney disease, should we reconsider? BMC Nephrol 17: 80.

65. Wesson D, Jo C, Simoni J (2015) Angiotensin II-mediated GFR decline in subtotal nephrectomy is due to acid retention associated with reduced GFR. Nephrol Dial Transplant 30(5): 762-770.

66. Mitch W (2000) Are supplements of ketoacids and amino acids useful in treating patients with chronic renal failure? Wien Klin Wochenschr 112(20): 863-864.
67. Combe C, Deforges LC, Caix J, Pommereau A, Marot D, et al. (1993) Compliance and effects of nutritional treatment on progression and metabolic disorders of chronic renal failure. Nephrol Dial Transplant 8(5): 412-418.

68. Menon V, Kopple JD, Wang X, Beck GJ, Collins AJ (2009) Effect of a very low-protein diet on long-term outcomes. Am J Kidney Dis 54(1): 183.

69. Barsotti G, Morelli E, Cupisti A, Bertoncini P, Giovannetti S (1991) A special, supplemented 'vegan' diet for nephrotic patients. Am J Nephrol 11(5): 380-385.

70. Chauveau P, Couzi L, Vendrely B, de Précigout V, Combe C, et al. (2009) Long-term outcome on renal replacement therapy in patients who previously received a keto acid-supplemented very-low-protein diet. Am J Clin Nutr 90(4): 969-974.

71. Levey A, Adler S, Caggiula A, England B, Greene T, et al. (1996) Effects of dietary protein restriction on the progression of advanced renal disease in the Modification of Diet in Renal Disease Study. Am J Kidney Dis 27(5): 652-663.

72. Menon V, Kopple J, Wang X, Beck G, Collins A, et al. (2009) Effect of a very low-protein diet on outcomes: Long-term follow-up of the Modification of Diet in Renal Disease (MDRD) Study. Am J Kidney Dis 53(2): 208-217.

73. Hansen H, Tauber-Lassen E, Jensen B, Parving H (2002) Effect of dietary protein restriction on prognosis in patients with diabetic nephropathy. Kidney Int 62(1): 220-228.

74. Barsotti G, Navalesi R, Giampetro 0, Ciardelle F, Morelli E, et al. (1988) Effects of a vegetarian, supplemented diet on renal function, proteinuria and glucose metabolism in patients with overt diabetic nephropathy and renal insufficiency. In Schmicker R, Kokot F, Gretz N, editors. Contributions to Nephrology, Metabolic Disturbances in the Predialytic Phase of Chronic Renal Failure. Karger; 87-94.

75. Piccoli G, Attini R, Vasario E, Conijn A, Biolcati M, et al. (2010) Pregnancy and chronic kidney disease: a challenge in all CKD stages. Clin J Am Soc Nephrol 5(5): 844-855.

76. Cabiddu G, Castellino S, Gernone G, Santoro D, Moroni G, et al. (2016) A best practice position statement on pregnancy in chronic kidney disease: the Italian Study Group on Kidney and Pregnancy. J Nephrol 29(3): 277-303.

77. Piccoli G, Fassio F, Attini R, Parisi S, Biolcati M, et al. (2012) Pregnancy in CKD: whom should we follow and why? Nephrol Dial Transplant 27(Suppl 3): iii111-118.

78. Vellanki K (2013) Pregnancy in chronic kidney disease. Adv Chronic Kidney 20(3): 223-228.

79. Piccoli G, Attini R, Vasario E, Gaglioti P, Piccoli E, et al. (2011) Vegetarian supplemented low-protein diets. A safe option for pregnant CKD patients: Report of 12 pregnancies in 11 patients. Nephrol Dial Transplant 26(1): 196-205.

80. Brenner B, Lawler E, Mackenzie H (1996) The hyperfiltration theory: a paradigm shift in nephrology. Kidney Int 49(6): 1774-1777.

81. Piccoli G, Leone F, Attini R, Parisi S, Fassio F, et al. (2014) Association of Low-Protein Supplemented Diets with Fetal Growth in Pregnant Women with CKD. Clin J Am Soc Nephrol 9(5): 864-873.

82. Attini R, Leone F, Montersino B, Fassio F, Minelli F, et al. (2017) Pregnancy, Proteinuria, Plant-Based Supplemented Diets and Focal Segmental Glomerulosclerosis: A Report on Three Cases and Critical Appraisal of the Literature. Nutrients 9(7): E770.

83. Attini R, Leone F, Parisi S, Fassio F, Capizzi I, et al. (2016) Veganvegetarian low-protein supplemented diets in pregnant CKD patients: fifteen years of experience. BMC Nephrol 17(1): 132. 
84. Kopple J (2001) National kidney foundation K/DOQI clinical practice guidelines for nutrition in chronic renal failure. Am J Kidney Dis 37(1 Suppl 2): S66-570.

85. Chen W, Abramowitz M (2014) Metabolic acidosis and the progression of chronic kidney disease. BMC Nephrol 15: 55.

86. Huston H, Abramowitz M, Zhang Y, Greene T, Raphael K (2015) Net endogenous acid production and mortality in NHANES III. Nephrology (Carlton) 20(3): 209-215.

87. Bushinsky D, Chabala J, Gavrilov K, Levi-Setti R (1999) Effects of in vivo metabolic acidosis on midcortical bone ion composition. Am J Physiol 277(5 Pt 2): F813-F819.

88. Wesson D, Dolson G (1997) Endothelin-1 increases rat distal tubule acidification in vivo. Am J Physiol 273(4 Pt 2): F586-F594.

89. Wesson D, Simoni J (2009) Increased tissue acid mediates a progressive decline in the glomerular filtration rate of animals with reduced nephron mass. Kidney Int 75(9): 929-935.

90. Bellocq A, Suberville S, Philippe C, Bertrand F, Perez J, et al. (1998) Low environmental $\mathrm{pH}$ is responsible for the induction of nitric-oxide synthase in macrophages. Evidence for involvement of nuclear factorkappaB activation. J Biol Chem 273(9): 5086-5092.

91. Ng H, Chen H, Tsai Y, Yang Y, Lee C (2011) Activation of intrarenal renin-angiotensin system during metabolic acidosis. Am J Nephrol 34(1): 55-63.

92. Wood C, Isa A (1991) Intravenous acid infusion stimulates ACTH secretion in sheep. Am J Physiol 260(1 Pt 1): E154-E161.

93. Bellasi A, Di Micco L, Santoro D, Marzocco S, De Simone E, et al. (2016) Correction of metabolic acidosis improves insulin resistance in chronic kidney disease. BMC Nephrol 17: 158.

94. Simon E, Hamm L (2010) A basic approach to CKD. Kidney Int 77(7): 567-569.

95. Teta D (2015) Insulin resistance as a therapeutic target for chronic kidney disease. J Ren Nutr 25(2): 226-229.

96. de Brito-Ashurst I, Varagunam M, Raftery M, Yaqoob M (2009) Bicarbonate supplementation slows progression of CKD and improves nutritional status. J Am Soc Nephrol 20(9): 2075-2084.

97. Rysz J, Franczyk B, Ciałkowska-Rysz A, Gluba-Brzózka A (2017) The Effect of Diet on the Survival of Patients with Chronic Kidney Disease. Nutrients 9(5): pii: E495.

98. Wesson D, Simoni J (2010) Acid retention during kidney failure induces endothelin and aldosterone production which lead to progressive GFR decline, a situation ameliorated by alkali diet. Kidney Int 78(11): 11281135.

99. Raphael K, Murphy R, Shlipak M, Satterfield S, Huston H, et al. (2016) Bicarbonate Concentration, Acid-Base Status, and Mortality in the Health, Aging, and Body Composition Study. Clin J Am Soc Nephrol 11(2): 308-316.

100. Kovesdy C, Anderson J, Kalantar-Zadeh K (2009) Association of serum bicarbonate levels with mortality in patients with non-dialysis-dependent CKD. Nephrol Dial Transplant 24(4): 1232-1237.

101. Navaneethan S, Schold J, Arrigain S, Jolly S, Wehbe E, et al. (2011) Serum bicarbonate and mortality in stage 3 and stage 4 chronic kidney disease. Clin J Am Soc Nephrol 6(10): 2395-2402.

102. Dobre M, Yang W, Chen J, Drawz P, Hamm L, et al. (2013) Association of Serum Bicarbonate With Risk of Renal and Cardiovascular Outcomes in CKD: A Report From the Chronic Renal Insufficiency Cohort (CRIC) Study. Am J Kidney Dis 62(4): 670-678.

103. Shah S, Abramowitz M, Hostetter T, Melamed M (2009) Serum Bicarbonate Levels and the Progression of Kidney Disease: A Cohort Study. Am J Kidney Dis 54(2): 270-277.
104. Chauveau P, Lasseur C, Nodimar C, Prezelin-Reydit M, Trolonge S, et al. (2018) Dietary acid load: A novel target for the nephrologist? Nephrol Ther 14(4): 240-246.

105. Banerjee T, Crews D, Wesson D, Tilea A, Saran R, et al. (2015) High Dietary Acid Load Predicts ESRD among Adults with CKD. J Am Soc Nephrol 26(7): 1693-1700.

106. Wesson D, Nathan T, Rose T, Simoni J, Tran R (2007) Dietary protein induces endothelin-mediated kidney injury through enhanced intrinsic acid production. Kidney Int 71(3): 210-217.

107. Di Iorio B, Di Micco L, Marzocco S, De Simone E, De Blasio A, et al. (2017) Very Low-Protein Diet (VLPD) Reduces Metabolic Acidosis in Subjects with Chronic Kidney Disease: The "Nutritional Light Signal" of the Renal Acid Load. Nutrients 9(1): pii: E69.

108. Adeva M, Souto G (2011) Diet-induced metabolic acidosis. Clin Nutr 30(4): 416-421.

109. Alpern R, Sakhaee K (1997) The clinical spectrum of chronic metabolic acidosis: Homeostatic mechanisms produce significant morbidity. Am J Kidney Dis 29(2): 291-302.

110. Kurtz I (1991) Role of Ammonia in the Induction of Renal Hypertrophy. Am J Kidney Dis 17(6): 650-653.

111. Mitch W, Medina R, Grieber S, May R, England B, et al. (1994) Metabolic acidosis stimulates muscle protein degradation by activating the adenosine triphosphate-dependent pathway involving ubiquitin and proteasomes. J Clin Invest 93(5): 2127-2133.

112. Kobayashi S, Maesato K, Moriya H, Ohtake T, Ikeda T (2005) Insulin resistance in patients with chronic kidney disease. Am J Kidney Dis 45(2): 275-280.

113. Mak R (1998) Effect of metabolic acidosis on insulin action and secretion in uremia. Kidney Int 54(2): 603-607.

114. Kurella M, Lo J, Chertow G (2005) Metabolic syndrome and the risk for chronic kidney disease among nondiabetic adults. J Am Soc Nephrol 16(7): 2134-2140.

115. Tyson C, Lin P, Corsino L, Batch B, Allen J, et al. (2016) Short-term effects of the DASH diet in adults with moderate chronic kidney disease: A pilot feeding study. Clin Kidney J 9(4): 592-598.

116. Wesson D, Jo C, Simoni J (2012) Angiotensin II receptors mediate increased distal nephron acidification caused by acid retention. Kidney Int 82(11): 1184-1194.

117. Goraya N, Wesson D (2014) Is dietary acid a modifiable risk factor for nephropathy progression? Am J Nephrol 39(2): 142-144.

118. Goraya N, Wesson D (2015) Dietary interventions to improve outcomes in chronic kidney disease. Curr Opin Nephrol Hypertens 24(6): 505-510.

119. Phisitkul S, Khanna A, Simoni J, Broglio K, Sheather S, et al. (2010) Amelioration of metabolic acidosis in patients with low GFR reduced kidney endothelin production and kidney injury, and better preserved GFR. Kidney Int. 77(7): 617-623.

120. Goraya N, Wesson D (2013) Does correction of metabolic acidosis slow chronic kidney disease progression? Curr Opin Nephrol Hypertens 22(2): 193-197.

121. Goraya N, Wesson D (2012) Acid-base status and progression of chronic kidney disease. Curr Opin Nephrol Hypertens 21(5): 552556.

122. Phisitkul S, Hacker C, Simoni J, Tran R, Wesson D (2008) Dietary protein causes a decline in the glomerular filtration rate of the remnant kidney mediated by metabolic acidosis and endothelin receptors. Kidney Int 73(2): 192-199. 
123. Scialla J, Appel L, Wolf M, Yang W, Zhang X, et al. (2012) Plant Protein Intake Is Associated with Fibroblast Growth Factor 23 and Serum Bicarbonate in Patients with CKD: The Chronic Renal Insufficiency Cohort Study. J Ren Nutr 22(4): 379-388.

124. Lin J, Hu F, Curhan G (2010) Associations of diet with albuminuria and kidney function decline. Clin J Am Soc Nephrol 5(5): 836-843.

125. Huang X, Stenvinkel P, Qureshi A, Cederholm T, Bárány P, et al. (2013) Clinical determinants and mortality predictability of stearoyl-CoA desaturase- 1 activity indices in dialysis patients. J Intern Med 273(3): 263-272

126. Huang X, Stenvinkel P, Qureshi A, Risérus U, Cederholm T, et al (2012) Essential polyunsaturated fatty acids, inflammation and mortality in dialysis patients. Nephrol Dial Transplant 27(9): 3615-3620.

127. Kataria A, Trasande L, Trachtman H (2015) The effects of environmental chemicals on renal function. Nat Rev Nephrol 11(10): 610625

128. Sears M, Genuis S (2012) Environmental Determinants of Chron ic Disease and Medical Approaches: Recognition, Avoidance, Supportive Therapy, and Detoxification. J Environ Public Health 2012 356798.

129. Bergkvist C, Oberg M, Appelgren M, Becker W, Aune M, et.al. (2008) Exposure to dioxin-like pollutants via different food commodities in Swedish children and young adults. Food Chem Toxicol 46(11): 3360-3367.

130. (2012) IARC Working Group on the Evaluation of Carcinogenic Risk to Humans. (2012) 2, 3, 7, 8 tetrachlorodibenzo-para-dioxin, 2, 3, 4 7, 8-pentachlorodibenzofuran, and 3, 3, 4, 4'5-pentachlorobiphenyl. In Chemical agents and related occupations. Lyon (France): International Agency for Research on Cancer pp. 339-378.

131. Everett C, Thompson O (2014) Dioxins, furans and dioxin-like PCBs in human blood: causes or consequences of diabetic nephropathy? Environ Res 132: 126-131.

132. Milbrath M, Wenger Y, Chang C, Emond C, Garabrant D, et al. (2009) Apparent Half-Lives of Dioxins, Furans, and Polychlorinated Biphenyls as a Function of Age, Body Fat, Smoking Status, and Breast-Feeding. Environ Health Perspect 117(3): 417-425.

133. Patanè G, Anello $M$, Piro $S$, Vigneri R, Purrello F, et al. (2002) Role of ATP production and uncoupling protein-2 in the insulin secretory defect induced by chronic exposure to high glucose or free fatty acids and effects of peroxisome proliferator-activated receptor-gamma inhibition. Diabetes 51(9): 2749-2756.

134. Kluwe W, Hook J (1980) Effects of environmental chemicals on kidney metabolism and function. Kidney Int 18(5): 648-655.

135. Everett C, Thompson O (2015) Association of DDT and heptachlor epoxide in human blood with diabetic nephropathy. Rev Environ Health. 30(2): 93-97.

136. Kitamura K, Nagao M, Yamada T, Sunaga M, Hata J, et al. (2001) Dioxins in bile in relation to those in the human liver and blood. J Toxicol Sci 26(5): 327-336.

137. Tremaine L, Quebbemann A (1985) The renal handling of terephthalic acid. Toxicol Appl Pharmacol 77(1): 165-174.

138. Frederiksen H, Skakkebaek N, Andersson A (2007) Metabolism of phthalates in humans. Mol Nutr Food Res 51(7): 899-911.

139. Hauser R, Meeker J, Park S, Silva M, Calafat A (2004) Temporal variability of urinary phthalate metabolite levels in men of reproductive age. Environ Health Perspect 112(17): 1734-1740.

140. Lee Y, Bae S, Lee S, Jacobs DJ, Lee D (2013) Persistent organic pollutants and hyperuricemia in the U.S. general population. Atherosclerosis. 230(1): 1-5.
141. Evenepoel P, Meijers B, Bammens B, Verbeke K (2009) Uremic toxins originating from colonic microbial metabolism. Kidney Int Suppl. (114): S12-S19.

142. Rossi M, Johnson D, Xu H, Carrero J, Pascoe E, et al. (2015) Dietary protein-fiber ratio associates with circulating levels of indoxyl sulfate and p-cresyl sulfate in chronic kidney disease patients. Nutr Metab Cardiovasc Dis. 25(9): 860-865.

143. Snelson M, Clarke R, Coughlan M (2017) Stirring the Pot: Can Dietary Modification Alleviate the Burden of CKD? Nutrients 9(3): E265.

144. Meijers B, Evenepoel P (2011) The gut-kidney axis: Indoxyl sulfate p-cresyl sulfate and CKD progression. Nephrol Dial Transplant 26(3): 759-761.

145. Niwa T (2010) Indoxyl sulfate is a nephro-vascular toxin. J Ren Nutr 20(5 Suppl): S2-6.

146. Tumur Z, Shimizu H, Enomoto A, Miyazaki H, Niwa T (2010) Indoxyl sulfate upregulates expression of ICAM-1 and MCP-1 by oxidative stress-induced NF-kappaB activation. Am J Nephrol 31(5): 435-441.

147. Bammens B, Evenepoel P, Keuleers H, Verbeke K, Vanrenterghem Y (2006) Free serum concentrations of the protein-bound retention solute p-cresol predict mortality in hemodialysis patients. Kidney Int 69(6): 1081-1087

148. Liabeuf S, Barreto D, Barreto F, Meert N, Glorieux G, et al. (2010) Free p-cresylsulphate is a predictor of mortality in patients at different stages of chronic kidney disease. Nephrol Dial Transplant 25(4): 1183-1191.

149. Patel K, Luo F, Plummer N, Hostetter T, Meyer T (2012) The Production of p-Cresol Sulfate and Indoxyl Sulfate in Vegetarians versus Omnivores. Clin J Am Soc Nephrol 7(6): 982-988.

150. Kandouz S, Mohamed A, Zheng Y, Sandeman S, Davenport A (2016) Reduced protein bound uraemic toxins in vegetarian kidney failure patients treated by haemodiafiltration. Hemodial Int 20(4): 610-617.

151. Koeth R, Wang Z, Levison B, Buffa J, Org E, et al. (2013) Intestinal microbiota metabolism of L-carnitine, a nutrient in red meat, promotes atherosclerosis. Nat Med 19(5): 576-585.

152. Rampton D, Cohen S, Crammond V, Gibbons J, Lilburn M, Rabet J, et al. (1984) Treatment of chronic renal failure with dietary fiber. Clin Nephrol 21(3): 159-163.

153. Salmean Y, Segal M, Langkamp-HB, Canales M, Zello G, et al. (2013) Foods With Added Fiber Lower Serum Creatinine Levels in Patients With Chronic Kidney Disease. J Ren Nutr 23(2): e29-32.

154. Salmean Y, Segal M, Palii S, Dahl W (2015) Fiber supplementation lowers plasma p-Cresol in chronic kidney disease patients. J Ren Nutr 25(3): 316-320

155. Bliss D, Stein T, Schleifer C, Settle R (1996) Supplementation with gum arabic fiber increases fecal nitrogen excretion and lowers serum urea nitrogen concentration in chronic renal failure patients consuming a low-protein diet. Am J Clin Nutr 63(3): 392-398.

156. Ali A, Ali K, Fadlalla A, Khalid K (2008) The effects of gum arabic oral treatment on the metabolic profile of chronic renal failure patients under regular haemodialysis in Central Sudan. Nat Prod Res. 22(1) $12-21$

157. Meijers B, Preter De V, Verbeke K, Vanrenterghem Y, Evenepoel P (2010) p-Cresyl sulfate serum concentrations in haemodialysis patients are reduced by the prebiotic oligofructose-enriched inulin. Nephrol Dial Transplant 25(1): 219-224

158. Sirich T, Plummer N, Gardner C, Hostetter T, Meyer T (2014) Effect of Increasing Dietary Fiber on Plasma Levels of Colon-Derived Solutes in Hemodialysis Patients. Clin J Am Soc Nephrol 9(9): 1603-1610. 
159. Fernandez PR, Esteras R, Perez-GM, Gracia-IC, Gonzalez-PE, et al (2017) Nutrients turned into toxins: microbiota modulation of nutrient properties in chronic kidney disease. Nutrients 9(5): E489.

160. Evenepoel P, Meijers B (2012) Dietary fiber and protein: Nutritional therapy in chronic kidney disease and beyond. Kidney Int. 81(3): 227-229.

161. Cupisti A, D’Alessandro C, Valeri A, Capitanini A, Meola M, et al (2010) Food Intake and Nutritional Status in Stable Hemodialysis Patients. Ren Fail 32(1): 47-54.

162. Kalantar-Zadeh K, Kopple J, Deepak S, Block D, Block G (2002) Food intake characteristics of hemodialysis patients as obtained by food frequency questionnaire. J Ren Nutr 12(1): 17-31.

163. Khoueiry G, Waked A, Goldman M, El-Charabaty E, Dunne E, et al (2011) Dietary Intake in Hemodialysis Patients Does Not Reflect a Heart Healthy Diet. J Ren Nutr 21(6): 438-447.

164. Lu L, Huang Y, Wang M, Chen D, Wan H, et al. (2017) Dietary fiber intake is associated with chronic kidney disease (CKD) progression and cardiovascular risk, but not protein nutritional status, in adults with CKD. Asia Pac J Clin Nutr 26(4): 598-605.

165. Kalantar-Zadeh K, Gutekunst L, Mehrotra R, Kovesdy C, Bross R, et al. (2010) Understanding sources of dietary phosphorus in the treatment of patients with chronic kidney disease. Clin J Am Soc Nephrol 5(3): 519-530.

166. Moe S, Zidehsarai M, Chambers M, Jackman L, Radcliffe J, et al. (2011) Vegetarian compared with meat dietary protein source and phosphorus homeostasis in chronic kidney disease. Clin J Am Soc Nephrol. 6(2): 257-264.

167. Kloppenburg W, Stegeman C, Hovinga T, Vastenburg G, Vos P, et al. (2004) Effect of prescribing a high protein diet and increasing the dose of dialysis on nutrition in stable chronic haemodialysis patients: A randomized, controlled trial. Nephrol Dial Transplant 19(5): 12121223.

168. Cupisti A, Kalantar-Zadeh K (2013) Management of Natural and Added Dietary Phosphorus Burden in Kidney Disease. Semin Nephrol 33(2): 180-190.

169. Uribarri J (2007) Phosphorus homeostasis in normal health and in chronic kidney disease patients with special emphasis on dietary phosphorus intake. Semin Dial 20(4): 295-301.

170. Lynch K, Lynch R, Curhan G, Brunelli S (2011) Prescribed Dietary Phosphate Restriction and Survival among Hemodialysis Patients. Clin J Am Soc Nephrol 6(3): 620-629.

171. Bover J, Andrés E, Lloret M, Aguilar A, Ballarín J (2009) Dietary and pharmacological control of calcium and phosphate metabolism in dialysis patients. Blood Purif 27: 369-386.

172. Uribarri J, Calvo M (2003) Hidden sources of phosphorus in the typical American diet: does it matter in nephrology? Semin Dial. 16(3): 186-168.

173. Calvo M, Moshfegh A, Tucker K (2014) Assessing the Health Impact of Phosphorus in the Food Supply: Issues and Considerations. Adv Nutr 5(1): 104-113.

174. Azadbakht L, Esmaillzadeh A (2009) Soy protein consumption and kidney related biomarkers among type 2 diabetics: a crossover, randomized clinical trial. J Ren Nutr 19(6): 479-486.

175. Jing Z, Wei-Jie Y (2016) Effects of soy protein containing isoflavones in patients with chronic kidney disease: A systematic review and meta-analysis. Clin Nutr 35(1): 117-124.

176. Chen X, Wei G, Jalili T, Metos J, Giri A, et al. (2016) The associations of plant protein intake with all-cause mortality in CKD. Am J Kidney Dis 67(3): 423-430.
177. Neven E, D'Haese P (2011) Vascular calcification in chronic renal failure: what have we learned from animal studies? Circ Res 108(2): 249-264.

178. Chauveau P, Combe C, Fouque D, Aparicio M (2013) Vegetarianism: advantages and drawbacks in patients with chronic kidney diseases. J Ren Nutr 23(6): 399-405.

179. Bergesio F, Monzani G, Guasparini A, Ciuti R, Gallucci M, et al. (2005) Cardiovascular risk factors in severe chronic renal failure: the role of dietary treatment. Clin Nephrol 64(2): 103-112.

180. Nongnuch A, Davenport A (2015) The effect of vegetarian diet on skin autofluorescence measurements in haemodialysis patients. Br J Nutr 113(7): 1040-1043.

181. Cupisti A, D'Alessandro C, Gesualdo L, Cosola C, Gallieni M, et al. (2017) Non-traditional aspects of renal diets: focus on fiber, alkali and vitamin K1 intake. Nutrients 9(5): E444.

182. Cupisti A, Aparicio M, Barsotti G (2007) Potential benefits of renal diets on cardiovascular risk factors in chronic kidney disease patients. Ren Fail 29(5): 529-534.

183. Bergesio F, Monzani G, Ciuti R, Cirami C, Martinelli F, et al. (2001) Autoantibodies against oxidized LDL in chronic renal failure: role of renal function, diet, and lipids. Nephron 87(2): 127-133.

184. Monzani G, Bergesio F, Ciuti R, Ciciani A, Martinelli F, et al. (1997) $\mathrm{Lp}(\mathrm{a})$ levels: effects of progressive chronic renal failure and dietary manipulation. J Nephrol 10(1): 41-45.

185. De Nicola L, Minutolo R, Chiodini P, Zoccali C, Castellino P, et al. (2006) Global approach to cardiovascular risk in chronic kidney disease: reality and opportunities for intervention. Kidney Int 69(3): 538-545.

186. Bakris G, Weir M, Shanifar S, Zhang Z, Douglas J, et al. (2003) Effects of blood pressure level on progression of diabetic nephropathy. Results from the RENAAL Study. Arch Intern Med 163(13): 1555-1565.

187. Jafar T, Stark P, Schmid C, Landa M, Maschio G, et al. (2003) Progression of chronic kidney disease: the role of blood pressure control, proteinuria, and angiotensin-converting enzyme inhibition. Ann Intern Med 139(4): 244-252.

188. Bakris G, Williams M, Dworkin L, Elliott W, Epstein M, et al. (2000) Preserving renal function in adults with hypertension and diabetes: a consensus approach: National Kidney Foundation Hypertension and Diabetes Executive Committees Working Group. Am J Kidney Dis 36(3): 646-661.

189. De Nicola L, Minutolo R, Bellizzi V, Zoccali C, Cianciaruso B, et al (2004) Achievement of target blood pressure levels in chronic kidney disease: a salty question? Am J Kidney Dis 43(5): 782-795.

190. Sarnak M, Levey A, Schoolwerth A, Coresh J, Culleton B, et al. (2003) Kidney disease as a risk factor for development of cardiovascular disease. A statement from the American Heart Association Councils on kidney in cardiovascular disease, high blood pressure research, clinical cardiology, and epidemiology and prevention. Hypertension 42(5): 1050-1065.

191. Keith D, Nichols G, Gullion C, Brown J, Smith D (2004) Longitudinal follow-up and outcomes among a population with chronic kidney disease in a large managed care organization. Arch Intern Med 164(6): 659-663.

192. Go A, Chertow G, Fan D, McCulloch C, Hsu C (2004) Chronic kidney disease and the risks of death, cardiovascular events and hospitalization. N Engl J Med 351(13): 1296-1305.

193. Sarnak M, Greene T, Wang X, Beck G, Kusek J, et al. (2005) The effect of a lower target blood pressure on the progression of kidney disease: long-term follow-up of the modification of diet in renal disease study. Ann Intern Med 142(5): 342-351. 
194. (2004) Kidney Disease Outcomes Quality Initiative (K/DOQI) K/ DOQI clinical practice guidelines on hypertension and antihypertensive agents in chronic kidney disease. Am J Kidney Dis 43(5 Suppl 1): S1-290.

195. Bellizzi V, Di Iorio B, De Nicola L, Minutolo R, Zamboli P, et al. (2007) Very low protein diet supplemented with ketoanalogs improves blood pressure control in chronic kidney disease. Kidney Int 71(3): 245-251.

196. Sacks F, Kass E. (1988) Low blood pressure in vegetarians: effects of specific foods and nutrients. Am J Clin Nutr 48(3 Suppl): 795-800.

197. Chuang S, Chiu T, Lee C, Liu T, Tsao C, et al. (2016) Vegetarian diet reduces the risk of hypertension independent of abdominal obesity and inflammation: a prospective study. J Hypertens 34(11): 21642171.

198. Beilin L, Rouse I, Armstrong B, Margetts B, Vandongen R (1988) Vegetarian diet and blood pressure levels: incidental or causal association? Am J Clin Nutr 48(3 Suppl): 806-810.

199. Lindahl O, Lindwall L, Spångberg A, Stenram A, Ockerman P (1984) $A$ vegan regimen with reduced medication in the treatment of hypertension. Br J Nutr 52(1): 11-20.

200. Liu H, Liu J, Kuo K (2018) Vegetarian diet and blood pressure in a hospital-based study. Tzu Chi Med J 30(3): 176-180.

201. Chauveau P, Koppe L, Combe C, Lasseur C, Trolonge S, et al. (2018) Vegetarian diets and chronic kidney disease. Nephrol Dial Transplant.

202. Ahrari S, Moshki M, Bahrami M (2014) The relationship between social support and adherence of dietary and fluids restrictions among hemodialysis patients in Iran. J Caring Sci 3(1): 11-19.
203. Beto J, Schury K, Bansal V (2016) Strategies to promote adherence to nutritional advice in patients with chronic kidney disease: a narrative review and commentary. Int J Nephrol Renovasc Dis 9: 21-33.

204. Beto J, Ramirez W, Bansal V (2014) Medical nutrition therapy in adults with chronic kidney disease: integrating evidence and consensus into practice for the generalist registered dietitian nutritionist. J Acad Nutr Diet 114(7): 1077-1087.

205. Lambert K, Mullan J, Mansfield K (2017) An integrative review of the methodology and findings regarding dietary adherence in end stage kidney disease. BMC Nephrol 18(1): 318.

206. Plantinga L, Fink N, Harrington-Levey R, Finkelstein F, Hebah N, et al. (2010) Association of social support with outcomes in incident dialysis patients. Clin J Am Soc Nephrol 5(8): 1480-1488.

207. Jenkins D, Kendall C, Marchie A, Faulkner D, Wong J, et al. (2005) Direct comparison of a dietary portfolio of cholesterol-lowering foods with a statin in hypercholesterolemic participants. Am J Clin Nutr 81(2): 380-387.

208. Ornish D, Scherwitz L, Billings J, Brown S, Gould K, et al. (1998) Intensive Lifestyle Changes for Reversal of Coronary Heart Disease. JAMA. 280(23): 2001-2007.

209. Ornish D, Brown S, Scherwitz L, Billings J, Armstrong W, et al. (1990) Can lifestyle changes reverse coronary heart disease? The Lifestyle Heart Trial. Lancet 336(8708): 129-133.

210. National Institute of Diabetes and Digestive and Kidney Diseases (2015) National Institute of Diabetes and Digestive and Kidney Diseases, USA.

\begin{tabular}{|l|}
\hline \multicolumn{1}{|c|}{ Your next submission with Juniper Publishers } \\
will reach you the below assets \\
- Quality Editorial service \\
- Swift Peer Review \\
- Reprints availability \\
- E-prints Service \\
- Manuscript Podcast for convenient understanding \\
- Global attainment for your research \\
- Manuscript accessibility in different formats \\
( Pdf, E-pub, Full Text, Audio) \\
- Unceasing customer service \\
Track the below URL for one-step submission \\
https://juniperpublishers.com/online-submission.php \\
\hline
\end{tabular}

